\title{
GESTÃO ESCOLAR E A QUESTÃO DA FORMAÇÃO DE PROFESSORES EM UMA ESCOLA ESTADUAL DE TEMPO INTEGRAL
}

\author{
SCHOOL MANAGEMENT AND THE QUESTION OF TEACHER TRAINING IN \\ A STATE SCHOOL OF INTEGRAL TIME
}

Fernanda da Costa Guimarães Carvalho ${ }^{1}$

\section{Resumo}

Este artigo analisa como a gestão de uma Escola Estadual de Ensino Médio do Recife promove a formação dos professores em serviço. A abordagem utilizada foi qualitativa. Para recolha dos dados foram realizadas análise documental, observação participante e entrevista semiestruturada com onze (11) professores e a equipe gestora (Coordenador Pedagógico, Gestor e Vice-Gestor; Secretária). Constatamos uma prática democrática concreta, como mediação das contradições normativas instituídas e a organização emancipatória instituinte.

Palavras-chave: Escola de Tempo Integral. Formação de Professor. Gestão Escolar.

\section{Abstract}

1 Professora Adjunta do Departamento de Administração Escolar e Planejamento Educacional do Centro de Educação da Universidade Federal de Pernambuco. E-mail - fernandacgcarvalho@gmail.com

2 Graduada em Pedagogia e aluna do Curso de Sociologia do Centro de Filosofia e Ciências Humanas(CFCH) da Universidade Federal de Pernambuco. E-mail - suely.marilene @gmail.com

Revista de Administração Educacional, Recife, V. 1. No 2 - jul/dez. 2017 p. $49-70$ 
This article analyzes how the management of a State High School in Recife promotes the training of teachers in service. The approach used was qualitative. Data collection was performed through documentary analysis, participant observation and semi-structured interviews with eleven (11) Teachers and the management team (Pedagogical Coordinator, Manager and Deputy Manager, Secretary). We find a concrete democratic practice, as a mediation of the normative contradictions instituted and the emancipatory organization.

Key words: School of Integral Time. Teacher Training. School management.

\section{INTRODUÇÃO}

Este artigo foi construído a partir de uma pesquisa desenvolvida no período de 2014 a 2016 com o objetivo de analisar como a gestão democrática de uma Escola Pública de Ensino Médio, estadual e de tempo integral, da cidade de Recife, estava promovendo a formação permanente dos professores em serviço.

É imprescindível que a gestão da escola programe em seu cotidiano ações que fortaleçam a formação de professores em serviço a partir do intercâmbio de experiências culturais e cognitivas, por meio de ações democráticas e compartilhadas junto aos docentes. Paro, (1988) destaca que a gestão da escola pública gratuita e de qualidade pode oferecer contribuições importantes para a melhoria da qualidade do ensino no Brasil. Para tanto, é relevante que sejam pensadas propostas de formação permanente de professores em serviço. Tais investidas podem fortalecer a participação e a integração de todos os sujeitos da escola a fim de que, de fato e de direito, essas propostas contribuam para o aprimoramento das práticas escolares.

A partir de uma abordagem qualitativa iniciamos a pesquisa documental analisando os documentos oficiais como o Regimento e o Projeto Político-pedagógico da EREM; em seguida realizamos as observações participantes junto ao cotidiano de trabalho dos professores do Ensino Médio (dentro e fora de sala de aula); do gestor; do vice-gestor; do coordenador pedagógico e secretaria. Por fim, realizamos as entrevistas semiestruturadas

Revista de Administração Educacional, Recife, V. 1. No 2 - jul/dez. 2017 p. 49-70 
com todos os sujeitos que foram observados em seu cotidiano de trabalho. Nossos principais referenciais teóricos foram: Aguiar (2014); Brandão (2002); Freire (1990); Garcia (2000); Marcelo (1998). Durante a análise foi iniciada uma busca teórica e prática de significados para atingir níveis de compreensão mais aprofundados a propósito das possíveis contribuições da gestão, da coordenação pedagógica, na formação permanente de professores em exercício.

Salientamos que o estudo realizado no cotidiano de trabalho da Escola Estadual de Tempo Integral (EREM) pode contribuir para a produção de conhecimento na área de gestão escolar, coordenação pedagógica e formação de Professores, compartilhando experiências e fomentando o debate tendo em vista a relevância no propósito de fazer da escola um espaço de reflexão sistemática e contínua. Um espaço de intercâmbio pedagógico, político e social.

Dividimos esse artigo em três seções teóricas $\mathrm{Na}$ primeira evidenciaremos os conceitos referentes à gestão democrática; em seguida trataremos sobre a formação de professores; na terceira, faremos uma abordagem a propósito do Coordenador Pedagógico (C P) e os desafios na construção das práticas de formação permanente, de professor em serviço. Ao final, apresentaremos algumas informações referentes ao público-alvo da pesquisa, metodologia e análise dos resultados obtidos.

\section{Gestão Democrática na Escola Pública}

O Artigo 206 da Constituição Federal de 1988 estabeleceu os princípios segundo os quais o ensino deve ser ministrado em todo o território nacional. Em seu inciso VI, institui a gestão democrática no ensino da escola na forma da Lei. A propósito da gestão democrática, Paro (1988) salienta que "cada vez mais se afirma a participação da comunidade (especialmente dos pais), junto às instituições de ensino" (p. 79). Contudo, tal participação não se deve limitar a funcionar apenas como um instrumento de controle democrático, mas também como uma necessidade do próprio empreendimento pedagógico.

Revista de Administração Educacional, Recife, V. 1. No 2 - jul/dez. 2017 p. 49-70 
Isso significa resgatar o papel da escola como lugar de reflexão, de ação, de reinvenção. Brandão (2002) nos aponta a importância do educador refletir sobre o processo educacional, sobre as práticas pedagógicas, a política e a gestão escolar. A participação de todos os sujeitos é uma condição para elaboração do Projeto Político-pedagógico da escola. O referido autor continua seu pensamento afirmando que "participar é uma forma de superar as condições de dominação: quanto maior o nível de participação, maior o êxito do trabalho" (p.12). Contudo, promover tais investidas é função do Coordenador Pedagógico. O Coordenador Pedagógico não pode agir solitário uma vez que a formação continuada na escola e fora dela dependem das condições de trabalho oferecidas, dependem da responsabilidade da equipe gestora, do $\mathrm{C} P$.

Assim torna-se essencial lembrar que a democratização da escola não se reduz à instituição da eleição para diretor. Fernandes (1986) nos impele a pensar que a democracia é uma realidade histórica a ser construída. Assim, é relevante que, progressivamente, na sociedade e na escola, sejam criadas relações de trabalho calcadas na colaboração recíproca e fundada, não na imposição, mas no diálogo. Azevedo (2001) destaca que "torna-se cada vez mais nebuloso o arco das forças e interesses que o Estado passa a representar" (p. 40). É fato que, para ultrapassar os obstáculos criados pelo Estado e pelo próprio sistema produtivo, é imprescindível que a escola seja detentora de um mínimo de saber e de poder de decisão que possa ser compartilhado por seus usuários de maneira mais efetiva e democrática.

Para Basto (2000), "a gestão democrática restabelece o controle da sociedade civil sobre a educação e sobre a escola pública" (p.20). E acrescenta: "a gestão democrática é incluída no rol das práticas sociais que podem contribuir para a consciência democrática e a participação popular” (p. 22). Nesse sentido, compreendemos a gestão compartilhada e participativa enquanto um instrumento significativo para a garantia do direito ao ensino público de qualidade e para o fortalecimento do trabalho de formação permanente de professores em serviço na escola pública.

Revista de Administração Educacional, Recife, V. 1. No 2 - jul/dez. 2017 p. 49-70 
É fato que a gestão democrática da escola, no Brasil, reivindicada pelos movimentos sociais durante o período da ditadura militar, tornou-se um dos princípios da educação na Constituição Brasileira de 1988, a ser aplicada apenas ao ensino da administração pública.

Podemos ainda salientar que o trabalho compartilhado pode favorecer a formação continuada de professores no espaço escolar, a partir do intercâmbio de experiências pedagógicas, culturais e administrativas. Contudo sabemos que os desafios são muitos.

Destacamos que a escola pode oportunizar a construção das competências necessárias para enfrentar uma desigual correlação de forças que vem se explicitando progressivamente, seja pela imposição de processos e técnicas de gestão, pelo controle do conhecimento na escola, pelo arrocho salarial dos professores e funcionários, pelo sucateamento dos equipamentos da escola, seja pelo confisco do direito à formação continuada no local de trabalho. Para Garrido (2015) a estrutura da gestão escolar pode: "facilitar ou dificultar a implementação do Projeto de Formação Continuada" (p.16). É fato também que o trabalho da gestão da escola, poderá ainda facilitar ou dificultar o trabalho do Coordenador Pedagógico (C P) ou Educador de Apoio, como é denominado esse profissional no Estado de Pernambuco.

Sabemos que para a Gestão da escola, para a Coordenação Pedagógica ter sucesso nos trabalhos de integração e formação permanente dos professores em serviço no cotidiano escolar é necessário que os professores das escolas públicas sejam contratados para uma jornada de trabalho na qual "teriam de atuar na docência; em atividades pedagógicas administrativas e em atividades de formação continuada e em serviço na própria escola (no coletivo) e fora dela" (GARRIDO,2015,p.22). Essas novas competências impelem o educador a conhecer ainda mais o cotidiano escolar e a valorizar e incentivar o intercâmbio de experiências, a comunicação, a inovação. Entretanto, os desafios em garantir tais investidas terminam comprometendo a formação permanente do professor em serviço, mesmo quando temos os professores, com a desejada dedicação exclusiva, como o caso dos docentes observados na EREM analisada neste artigo.

Revista de Administração Educacional, Recife, V. 1. No 2 - jul/dez. 2017 p. $49-70$ 
Os estudiosos Freire e Donaldo (1990) assim colocam: "A participação social, o exercício da cidadania contêm em si o conhecimento da realidade e a autoformação" (p. 91). A identidade dos educandos e dos professores, as práticas pedagógicas e os conteúdos curriculares devem ser compreendidos como partes representativas de um conjunto de interesses subjacentes, que estruturam o modo através do qual determinadas relações sociais se fortalecem e são transformadas e/ou substituídas. Neste sentido propomos na próxima seção uma abordagem a propósito do Artigo 60 da LDB de 1996 e uma reflexão sobre a relevância da formação de professores em serviço para a melhoria da qualidade dos serviços prestados pela escola. Destacamos em seguida a função do Coordenador Pedagógico.

\section{Formação Permanente de Professor em Serviço}

Um dos mais significativos avanços da legislação no que se refere à formação de professores consta no Artigo 61 da Lei de Diretrizes e Bases da Educação de 1996: "encontramos que a formação de profissionais da educação deve atender aos diferentes níveis e modalidades de ensino, assim como às características de cada fase do desenvolvimento" (GRINSPUIN, 2002, p. 24). A autora em questão destaca que "há uma inovação muito grande, na medida em que o Art. 61- Inciso I proclama, textualmente, a associação entre teorias e práticas, inclusive mediante a capacitação em serviço" (p.56). Também encontramos pontos positivos nessa lei em termos da valorização dos profissionais da educação, destacando-se pontos significativos, como: "o aperfeiçoamento do profissional de forma contínua, inclusive com licenciamento periódico remunerado para esse fim" (Art. 61, Inciso II). Outras questões relevantes dessa lei referem-se à avaliação de desempenho do professor (Inciso IV), bem como à determinação, via legal, de períodos reservados a estudo, planejamento e avaliação, incluídos na carga de trabalho (Inciso V). Desse modo, o que já acontecia no cotidiano de trabalho de algumas instituições e que já

Revista de Administração Educacional, Recife, V. 1. No 2 - jul/dez. 2017 p. $49-70$ 
tinha sido objeto de documentos legais Municipais, Estaduais e Federais passa a ser determinação da Lei de Diretrizes e Bases - Lei 9394 de 1996.

Vale salientar a urgência da organização dos docentes no âmbito escolar para que não somente a formação permanente de professores aconteça de fato, como também que os momentos para estudo, planejamento e avaliação façam parte das atividades cotidianas do professor na escola.

Marcelo (1998) contribui para as análises nesta pesquisa, com relação à relevância da formação contínua de professores, quando destaca suas reflexões a propósito da evolução das pesquisas sobre o tema e nos aponta mudanças significativas. Vejamos: "se inicialmente a pergunta que nos fazíamos era: 'o que é o ensino eficaz?", pouco a pouco apareceram outros questionamentos como: "o que os professores conhecem? Que conhecimento é essencial para o ensino? Quem produz conhecimento sobre ensino?” (p. 50). Assim, esse autor destaca que, ao mesmo tempo em que os problemas evoluíram, percebe-se também uma maior preocupação em ampliar e engrandecer os modelos de análise.

Observemos: "se inicialmente a preocupação centrava-se principalmente nos professores em formação, depois foi surgindo considerável literatura de pesquisa a respeito dos professores em exercício" (idem, ibidem, p.51). O autor em questão nos remete à importância de analisar a formação de professores em exercício enquanto uma reflexão dos processos de inovação e mudança; e ainda salienta: "suas implicações organizacionais, curriculares e didáticas fazem com que, cada vez mais, a pesquisa sobre formação de professores seja percebida como necessidade indiscutível" (idem, ibidem, p. 51). Os anos 2000, todavia, trazem para o centro do debate sobre a formação de professores a análise sobre a função política e social do Gestor, do Coordenador Pedagógico ou Educador de apoio, do Professor nesse processo de formação de professores.

Para Marcelo (1998), "se há um tema que surgiu com vigor nos últimos anos, obrigando a reformular os estudos sobre formação de professores, referimo-nos certamente

Revista de Administração Educacional, Recife, V. 1. No 2 - jul/dez. 2017 p. $49-70$ 
às pesquisas que se têm desenvolvido em torno do amplo descritor aprender a ensinar" (p. 51). Esse autor destaca que: "as pesquisas sobre aprender a ensinar evoluiu na direção da indagação sobre o processo pelos quais os professores geram conhecimento, além de sobre quais tipos de conhecimento adquirem" (p. 51). O que se pretende é compreender melhor a atuação do professor, é pensar em como se está fazendo o ensinar. A ideia destacada pelo referido autor constitui-se na concepção do professor como profissional reflexivo e na reflexão sobre a ação como estratégia que fundamenta a epistemologia da prática.

Vejamos a esse respeito o que afirma Aguiar (2014) a propósito da formação permanente: "é entendida como um espaço de criação e incentivo às trocas de experiências entre os professores e estudantes, de modo que se implante uma cultura colaborativa" (p. 04). A autora ainda destaca que "não basta saber sobre as dificuldades da profissão, é preciso refletir sobre elas e buscar soluções, de preferência, mediante ações coletivas" (p. 04). Essas ações nos impelem a buscar na gestão da escola o apoio necessário para a vivência das ações reflexivas no cotidiano da sala de aula, no cotidiano escolar.

A autora a pouco referida observa que "a formação permanente dos Professores não pode desconhecer esta realidade, deve articular-se com o desenvolvimento das organizações escolares" (AGUIAR,p.05). Para a autora em questão, temos que compreender a escola enquanto um ambiente educativo, onde trabalhar e formar não sejam atividades isoladas, mas articuladas.

\section{O Coordenador Pedagógico e os Desafios na Construção das Práticas de Formação Permanente do Professor em Serviço.}

Refletir hoje sobre a função do Coordenador Pedagógico (CP) é um dos principais desafios, Garrido (2015) destaca que o trabalho do Professor-Coordenador é fundamental para a construção da formação docente em serviço. Contudo, nosso primeiro passo

Revista de Administração Educacional, Recife, V. 1. No 2 - jul/dez. 2017 p. $49-70$ 
certamente é a conquista do horário da formação em serviço no cotidiano das atividades escolares. A autora, já referida anteriormente, destaca que o trabalho apesar de essencial é muito complexo, uma vez que "busca compreender a realidade escolar para construir alternativas" (p.10). Ela continua afirmando que "esse trabalho torna-se ainda mais difícil porque constitui uma prática nova" (p.11). E tudo só poderá funcionar bem se o diálogo entre o $\mathrm{CP}$, professores e equipe gestora reconhecer a relevância da construção do Horário de Trabalho Pedagógico Coletivo.

Sabemos que o CP terá que desenvolver habilidades, junto aos professores, que promova sobretudo à comunicação cotidiana, o intercâmbio de experiências pedagógicas, culturais e cognitivas entre os docentes. Guimarães e Villela (2015) destacam três níveis de atuação do Coordenador Pedagógico: "1- o de resolução de problemas; 2- o de prevenção de situações problemas previsíveis; 3 - o de promoção de situações saudáveis do ponto de vista educativo e sócio afetivo" (p.39). Os autores destacam que todas às fazes são significativas, contudo salientam: "não é difícil perceber que um trabalho voltado apenas para o nível 1, além de pouco produtivo, desgasta a figura do CP e de toda a escola" (p. 40). Nesse nível não há construção de projeto pedagógico, não há troca de experiências, não há problematização sobre a prática desencadeada pelos docentes, individualmente, no espaço escolar.

A seguir apresentaremos algumas considerações sobre a metodologia e os resultados registrados após o término da coleta e análise dos dados.

\section{METODOLOGIA}

É importante destacar que a pesquisa que deu origem a este artigo foi desenvolvida em uma

Revista de Administração Educacional, Recife, V. 1. No 2 - jul/dez. 2017 p. $49-70$ 
Escola Estadual de Referência em Ensino Médio (EREM) na cidade do Recife, no período de março de 2014 a março de 2016. A escolha da instituição atendeu aos seguintes critérios: ser de referência, de tempo integral e ter gestão democrática. Salientamos ainda que a escola foi selecionada porque já apresentava um histórico de inovações_políticopedagógicas. Nosso objetivo foi analisar se existiam, na referida instituição, ações referentes à formação permanente de professores em serviço, especificamente aqueles vinculados ao Ensino Médio.

Os dados coletados foram construídos por meio de uma pesquisa qualitativa, que contou com observações, entrevistas semiestruturadas e análise documental. Tais instrumentos nos possibilitaram uma maior compreensão do cotidiano de trabalho da EREM.

Para iniciarmos a coleta de dados, abordamos os professores do Ensino Médio a partir de Seminários Temáticos de Integração Pedagógica. Após tais investidas de socialização de experiências, que contou com a participação de professores do Departamento de Administração Escolar e Planejamento Educacional do Centro de Educação da Universidade Federal de Pernambuco, iniciamos a pesquisa no cotidiano daquela instituição de ensino.

A coleta de dados abrangeu vinte e quatro (24) meses e foi dividida em três fases: análise documental, observação e entrevistas. Iniciamos analisando os documentos da EREM: Projetos de Ensino; os Planos de Aula; o Regimento Escolar; o Projeto PolíticoPedagógico; o Projeto de Melhoria da Escola; o Plano de Desenvolvimento Escolar e as fichas de acompanhamento da aprendizagem dos alunos. Nosso objetivo foi aproximar a teoria (o que estava escrito nos documentos) as práticas vivenciadas pelos professores, dentro e fora da sala de aula, que iríamos observar na sequência de nossas ações de coleta

Revista de Administração Educacional, Recife, V. 1. No 2 - jul/dez. 2017 p. $49-70$ 
de dados. O fato é que pretendíamos verificar se os professores vivenciavam as atividades previamente planejadas e registradas nos documentos referidos acima.

Na segunda fase iniciamos as observações no cotidiano de trabalho da Gestão, do Coordenador Pedagógico, dos Professores do Ensino Médio e da Secretaria. A proposta era verificar se existia um projeto de formação permanente de professores em serviço. Pretendíamos identificar qual era o tempo reservado pelos docentes para: construção da aula, estudos, planejamentos, avaliação e intercâmbio de experiências cognitivas, culturais, sociais, como estabelece o Artigo 61 Inciso V da LDB, de 1996, já mencionada.

Durante as entrevistas, que aconteceram durante seis (6) meses, na terceira fase da geração dos dados, junto a onze (11) Professores; um Coordenador Pedagógico; uma Secretaria; um Gestor e um Vice - gestor, indagamos, a propósito de quais ações vivenciadas na escola (pela Coordenação Pedagógica, pela Gestão) fortaleciam a formação permanente de professores em exercício. A partir de entrevistas semiestruturadas, perguntamos aos docentes se eles estudavam e planejavam coletivamente; se vivenciavam projetos pedagógicos; se existia um projeto de formação permanente na escola e/ou na Secretaria de Educação do Estado de Pernambuco. Solicitamos ainda, dos entrevistados, uma avaliação a propósito do processo de aperfeiçoamento pedagógico vivenciado por eles na escola.

\section{RESULTADOS}

\section{a) Análise Documental}

Em relação aos documentos analisados constatamos que a escola afirma a

Revista de Administração Educacional, Recife, V. 1. No 2 - jul/dez. 2017 p. $49-70$ 
importância da formação permanente de professores em serviço; ressalta projetos de estudos, planejamento e salienta os princípios democráticos em sua gestão. Vejamos o que nos diz o Projeto Político-Pedagógico da EREM analisado no que refere-se aos objetivos e metas a serem vivenciados no período de 2014 a 2015 na escola: incentivar e apoiar projetos que enriqueçam as atividades curriculares e extracurriculares; elevar o desempenho dos alunos da escola; garantir uma gestão participativa; estimular a realização de ações diversificadas promovam uma metodologia inovadora voltada para a interdisciplinaridade; elevar os índices no IDEB e ENEM; promover a formação permanente de professores etc. (Documento).

Freire e Donaldo (1990) enfatizam que "a reinvenção é o trabalho da mente ativa; é um ato de conhecimento pelo qual reinventamos nosso discurso" (p.21). O autor continua seu pensamento salientando: "todos os educadores críticos são também educandos. Não se trata meramente de aprender a respeito do que os alunos devem saber; trata-se, muito mais, de aprender como renovar, uma forma de autoconhecimento mediante uma compreensão da comunidade" (p. 22). A formação de Professores em exercício compreendida enquanto um espaço de intercâmbio de experiências cognitivas, culturais e sociais é o incentivo ao trabalho cooperativo, colegiado e democrático.

Encontramos na Seção III, do Regimento da EREM, a função do Educador de Apoio ou Coordenador Pedagógico, vejamos:

aprimorar o desempenho profissional numa perspectiva de formação permanente; desenvolver junto aos professores um processo de formação continuada; incentivar, junto aos professores e estudantes, a produção de trabalhos escritos e outras experiências pedagógicas; assegurar a utilização das aulas-atividades para realização de trabalhos que resultem na melhoria das ações pedagógicas. (Documento).

Almeida, Placo e Souza (2011) salientam que a legislação referente às atribuições

Revista de Administração Educacional, Recife, V. 1. No 2 - jul/dez. 2017 p. 49-70 
do Coordenador Pedagógico (CP) são muitas e envolve: "a liderança do Projeto Político Pedagógico; funções administrativas de assessoramento da direção e atividades relativas ao funcionamento pedagógico da escola e à formação contínuada" (p.23). Sabemos que a função mais comprometida pelo acúmulo de tarefas desse profissional é a de acompanhamento pedagógico junto a todos os professores da escola e a de formação permanente em serviço. As dificuldades do $\mathrm{CP}$ em realizar suas funções com sucesso, muitas vezes impede o professor de refletir sobre o seu cotidiano de trabalho a partir de estudos e intercâmbio cultural e pedagógico, que poderiam ser estimulados cotidianamente a partir de dinâmicas interacionistas junto a todos os docentes.

Após a análise dos documentos constatamos que eles contemplam o que diz a legislação e os teóricos sobre a gestão democrática, formação permanente em serviço, embora o que observamos na prática e através das entrevistas com os professores difere do que está posto nos documentos da escola.

\section{b) Observações}

Durante as observações no cotidiano da escola: em sala de aula, junto à equipe gestora, à coordenação pedagógica e à secretaria, verificamos que não existia uma rotina de reuniões, de intercâmbio de experiências pedagógicas, de ações participativas, compartilhadas, entre os professores. Para Libânio (2002) as ações coletivas de estudo, de planejamento, de troca de experiências cognitivas, culturais, pedagógicas são formas "de gerir uma instituição de ensino, de maneira que possibilite a participação, a transparência, a democracia e a qualidade dos serviços educacionais prestados” (p. 54). Certamente tais investidas são grandes desafios na realidade complexa da prática educativa.

É o Gestor quem nos confirma a ausência de tais ações no cotidiano de trabalho da referida EREM: “a formação só acontece no dia da aula atividade, o professor pode

Revista de Administração Educacional, Recife, V. 1. № 2 - jul/dez. 2017 p. $49-70$ 
planejar suas atividades de sala, mas o planejamento só acontece no início do ano" (Gestor). Para Lima (2007) é imprescindível que seja desenvolvido, incentivado pela equipe gestora, pela coordenação pedagógica, os encontros coletivos, junto aos docentes para incentivar: "habilidades, atitudes, valores e conhecimentos que lhes possibilitem construir permanentemente seus saberes, sua docência e sua identidade" (p.43). Sabemos da relevância em estimular, no cotidiano de trabalho dos professores da Escola Estadual de Ensino Médio, o planejamento, o estudo coletivo e cotidiano, como estabelece o LDB de 1996, já referida anteriormente, e não apenas no início do ano letivo, como ocorre na referida instituição, para garantir o sucesso das atividades desenvolvidas naquela comunidade escolar.

Constatamos que as ações de inovações pedagógicas, organização de projetos, estudo e planejamento eram vivenciados, individualmente, e por poucos professores. As ações coletivas só foram observadas entre o gestor e o grupo de pais e/ou responsáveis pelos discentes. Os assuntos em foco, nos referidos encontros, eram sempre relacionados à burocracia; à distribuição de tablet; ao fardamento; à merenda etc. Vejamos o que o Gestor daquela EREM nos diz sobre sua função na escola: "O meu conceito de gestão escolar é uma questão muito ampla, a gente precisa de uma estrutura melhor. Para ser gestor você tem que ter domínio da demanda que é muito grande. É difícil você trabalhar sem ter um número suficiente de funcionários" (Gestor). O referido entrevistado salienta que na gestão democrática todos os seguimentos da escola devem ser estimulados a dialogar, a refletir os problemas cotidianos, mas conclui afirmando que a gestão da escola que ele administra é: "incompleta, não temos pessoas para trabalhar e os professores faltam muito" (Gestor).

Destacamos a urgência em estabelecer tais ações no cotidiano da escola estudada, uma vez que os poucos professores que tentavam vivenciar projetos pedagógicos inovadores terminavam encontrando obstáculos, intransponíveis, sem o apoio da equipe gestora, do Coordenador Pedagógico, ou Educador de Apoio como é denominada a função

Revista de Administração Educacional, Recife, V. 1. No 2 - jul/dez. 2017 p. $49-70$ 
deste profissional da educação no Estado de Pernambuco.

\section{c) Entrevista}

Vejamos o relato de um professor entrevistado: “esse ano para mim foi mais preso, não tive muita facilidade de aplicar projetos que exigiam sair da escola, pois minha rotina de trabalho atrapalhava outras disciplinas" (Professora 6). A referida docente finaliza a entrevista afirmando: "se eu construir um projeto diferenciado, que leve um tempo a mais, algumas turmas vão ficar sem aula e minha ausência é cobrada pela gestão" (Idem). Constatamos a partir da fala da Professora 6 que: a falta de comunicação; de planejamento coletivo; de intercâmbio de experiências pedagógicas entre os docentes, da EREM em questão nesta pesquisa, termina obstaculizando ações inovadoras que poderiam contribuir para o aumento da qualidade no ensino e a motivação entre os discentes.

Como nos informou a docente entrevistada: "não existem canais de comunicação entre os professores" (Professora 6). O fato é que o diálogo, o planejamento coletivo são determinações da LDB de 1996, não somente para Ensino Médio, mas para a educação brasileira.

Ainda sobre a gestão escolar podemos observar o que nos informa outro docente:

\footnotetext{
a gente não tem uma escola democrática. Quando comecei aqui na Escola Integral, pensei que as aulas práticas, extraclasse, iriam integrar o currículo do ensino médio, Mas quando saímos das salas com os alunos para a biblioteca, para os laboratórios, auditórios, os funcionários reclamam da desorganização e o Gestor barra o projeto. Os Professores só obedecem. ( Professor 4).
}

Para Garcia (2000), "a escola tem a função de fortalecer as competências que vão além do ensinar" (p.72). Assim, é importante a criação de canais institucionais capazes de viabilizar

Revista de Administração Educacional, Recife, V. 1. Nº 2 - jul/dez. 2017 p. 49-70 
essa troca de planejamento, de experiências escolares.

Guimarães e Villela (2015) salientam que a função do Coordenador Pedagógico (CP) é "ser capaz de identificar essa trama comunicativa para que exerça seu papel com sucesso" (p.39). Os autores destacam que é de vital importância que o CP e a equipe gestora sejam capazes de "discernir os diferentes níveis de sua atuação para que não dificulte o amadurecimento da escola" (p.39). É importante salientar que a gestão democrática pode constituir um caminho real de melhoria da qualidade do ensino, se ela for concebida, em profundidade, como um mecanismo capaz de alterar práticas pedagógicas e de fortalecer a formação permanente dos professores em serviço.

Não verificamos nenhuma proposta de projeto de ação, de formação permanente em serviço, direcionado aos professores, efetivada pela coordenação pedagógica. Dos quinze professores entrevistados somente um salientou ter vivenciado a hora atividade ofertada na Escola de Referência analisada. Vejamos o que ele nos informa sobre a experiência vivenciada:"na escola temos espaço para planejar nossas aulas. Nos preparamos para elaborar nossas atividades anuais. Temos dois (2) dias de formação para que o professor se sinta animado para iniciar o ano" (Professor 4). Apesar do entrevistado destacar dois dias de formação a cada início do ano letivo, todos os demais negaram qualquer investida da escola nesse sentido.

Observemos ainda o que nos diz a Coordenadora Pedagógica a este propósito:

os professores em geral não têm formação, nem hora atividade, para organizarem sua aula, sua avaliação. Não existe uma linha pedagógica definida na escola. Cada um faz sua aula como quer. Segue um horário que é estabelecido. A hora e o dia de cada disciplina e nada mais. Ainda temos que melhorar muito... Porém falta tempo para cumprir com as demandas legais no que se refere à

Revista de Administração Educacional, Recife, V. 1. No 2 - jul/dez. 2017 p. 49-70 
formação de professor no espaço da escola ...". (Coordenador Pedagógico).

Podemos ainda salientar o que nos diz outra docente sobre o assunto em questão: "hoje em dia é diferente, pois a formação de professores pode acontecer dentro da escola. Contudo, o professor tem autonomia para fazer. Para participar. O problema é que ele termina não participando. A frequência é baixa". (Professora 3) Podemos encontrar em outras falas de professores a justificativa da baixa frequência nos poucos momentos, apenas dois dias por ano, de formação de professores promovidos pela Escola, pela Secretaria de Educação na escola, vejamos:

você só tem teoria nas formações que são ministradas pela Secretaria de Educação do Estado de Pernambuco. É teoria em cima de teoria. E não muda nada, já tenho vinte e cinco anos de Estado. Depois da teoria o professor recebe um bocado de papel e depois tem que falar o que faz na sala. É um capacitação que virou corriqueira... É sempre a mesma coisa (Professora 5)

O sucesso da formação de professores em serviço depende da equipe gestora; das condições de trabalho oferecidas ao CP. E certamente seu o maior desafio é a organização e efetivação da hora atividade, do estudo e planejamento coletivo no cotidiano de trabalho dos professores na escola. Durante a entrevista com a CP foi destacado que: "a formação de professores poderia fortalecer uma análise crítica da aula, mais a entrevistada acrescenta que: "ninguém tem tempo para isso...". (Coordenador Pedagógico) A referida profissional reconhece que a formação de professores poderia ainda contribuir com a melhoria do ensino, mas lamenta que o corpo docente daquela EREM não tenha disponibilidade para tal investida.

Durante a entrevista com o C P, ele também lamentou a falta de investidas destinadas à formação dos professores na escola, a ausência de tempo destinado à troca de experiências. Vejamos o que ela nos diz: "a integração, a formação no cotidiano de trabalho

Revista de Administração Educacional, Recife, V. 1. No 2 - jul/dez. 2017 p. $49-70$ 
poderia proporcionar uma compreensão melhor da linha pedagógica de cada um... Um estudo sobre as ações pedagógicas viáveis para conquistar o sucesso dos alunos nas avaliações." (Coordenador Pedagógico). Ele ainda nos informou que: "a formação de professores não pode ser dois dias por ano: "Ela deve ser constante... Uma reflexão da prática pedagógica... No sentido de aperfeiçoamento do processo de ensino e aprendizagem" (Idem). Sabemos que o exercício da profissão de professor requer uma sólida formação, não somente para a produção da aula, mas também para a elaboração dos recursos didáticopedagógicos e teórico-metodológicos além do conhecimento da realidade.

A esse respeito, Placco, Almeida e Souza (2011) afirmam que: "para a superação das atividades cotidianas da escola, se exige um trabalho coletivo, que, por sua vez exige presença e a atuação de um articulador dos processos educativos que alí se dão.”(p.02). O próprio coordenador, muitas vezes, desconhece o seu papel de articulador. Os autores a pouco referidos ainda destacam que: "Esse articulador precisa agir nos espaços tempos diferenciados" (p.03). Nessa perspectiva, destacamos a importância da reconstrução do papel identitário desse profissional.

O Coordenador Pedagógico precisa ter clareza da sua função profissional. Salientamos a necessidade de este profissional, da gestão da escola, desencadearem discussões, reflexões a propósito da identidade e da autonomia do C P, uma vez que os dados coletados, no cotidiano de trabalho deste profissional, na EREM estudada, alertamnos para limitações significativas e prejudiciais ao amadurecimento político- pedagógico dos docentes da referida instituição e ao processo de formação permanente dos professores em exercício.

Para Aguiar (2014) "a formação dos Professores visa a inquietar os docentes para que possam: observar suas ações, ver os estudantes e analisar se o que está sendo feito traz resultados satisfatórios para ambos, o que precisa mudar e como melhorar esse processo de aprendizagem" (p. 04). A autora em questão nos alerta para a importância da formação permanente dos professores no que concerne à realização de um diagnóstico dos problemas

Revista de Administração Educacional, Recife, V. 1. No 2 - jul/dez. 2017 p. 49-70 
existentes na instituição, a fim de que essa realidade seja levada para uma discussão coletiva e, assim, possam ser elaboradas reflexões, ações e transformações.

Para tanto, a comunidade escolar deve refletir sobre a importância da gestão democrática, sobre sua função social, sobre as condições do trabalho e funcionamento das atividades cotidianas.

\section{CONSIDERAÇÕES FINAIS}

Após a análise documental constatamos em todos os documentos oficiais da escola, como o Projeto Político Pedagógico e o Regimento, a preocupação em organizar o cotidiano da instituição contemplando ações de: integração entre os segmentos que compõe a escola; de inovação e intercâmbio de experiências pedagógicas e culturais; de formação de Professores; de gestão democrática. Contudo, as observações e as entrevistas nos apontaram dificuldades em vivenciar tais investidas no cotidiano da Escola Estadual de Ensino Médio. O fato é que a maioria dos entrevistados afirma que os aspectos organizacionais vivenciados não promovem uma proposta de formação continuada para os professores em exercício que atenda às necessidades dos docentes. Já nos primeiros encontros - de caráter informal - e nas entrevistas, constatamos que os Professores:

- não vivenciam em seu cotidiano um processo coletivo de estudos, de reflexão e de planejamento;

- não cumprem o que explicita a LDB de 1996, em seu Artigo 61, no que se refere à formação permanente de professores em serviço.

Nessa perspectiva, este estudo nos permitiu constatar que os docentes não conseguem romper com o desânimo e a fadiga que terminam impregnando até os mais comprometidos com a luta pela educação de qualidade. Durante todo processo de coleta de dados, junto ao Coordenador Pedagógico (C P), a equipe gestora, indagávamos a propósito da ausência de um projeto que aproximasse a coordenação pedagógica dos docentes

Revista de Administração Educacional, Recife, V. 1. No 2 - jul/dez. 2017 p. $49-70$ 
vinculados ao Ensino Médio de tempo integral. Os profissionais em questão sempre destacavam que a gestão da escola estava proporcionando muito pouco para promover a formação permanente de professores em serviço.

Nesse sentido podemos pensar na urgência em ser desencadeado um processo de aplicação das exigências determinadas pela LDB, Lei 9394, de 1996, no Art. 61 . O fato é que torna-se cada vez mais relevante fortalecer os trabalhos da gestão, do Coordenador Pedagógico no cotidiano de trabalho da EREM analisada nesse artigo. As investidas no sentido de aprimorar a formação de Professores em exercício, a partir do fortalecimento dos trabalhos do Coordenador Pedagógico é de fato um desafio para a educação do século XXI. A este profissional caberá primeiramente o desafio de aprimorar o diálogo entre os professores.

\section{REFERÊNCIAS}

AGUIAR, M. C. C. Tendências e implicações da formação continuada para a identidade profissional docente universitária. Trabalho apresentado na $37^{\mathrm{a}}$ Reunião Anual da Associação Nacional de Pesquisa e Pós-graduação em educação (ANPED) Anais da 37 Reunião Anual da ANPED... Universidade Federal de Santa Catarina. (UFSC) Florianópolis, 2015.

AZEVEDO, J. M. L. Educação como política pública. Petrópolis, Rio de Janeiro: Vozes, 2001.

BASTO, J. B. Gestão democrática. Rio de Janeiro: DP\&A/SEPE, 2000.

BRANDÃO, C. R. Educação no Brasil. Brasília: Abril Cultural/ Brasiliense, 2002.

BRASIL. Lei 9394, de 24/12/1996. Lei de Diretrizes e Bases da Educação Nacional.

Estabelece as Diretrizes e Bases da Educação Nacional.

BRASIL. Lei 5692 de 1971. Estabelece a Reforma do Ensino. Brasília.

Revista de Administração Educacional, Recife, V. 1. No 2 - jul/dez. 2017 p. 49-70 
BRASIL. Constituição da República Federativa do Brasil. Brasília: Senado Federal, Centro Gráfico. 1988. (05/10/1988)

Brasília.

FERNANDAES, F. Nova República. Rio de Janeiro: Jorge Zahar, 1986.

FREIRE, Paulo; DONALDO, P. Alfabetização: leitura do mundo, leitura da palavra. São Paulo: Paz e Terra, 1990.

GARCIA, W. E. Administração educacional em crise. São Paulo: Cortez, 2000.

FARIA FILHO, L. M. O processo de escolarização em Minas: questões teóricometodológicas e perspectivas de análise. In: VEIGA, C. G.; FONSECA, T. N. L. (Orgs.).

História e Historiografia da Educação no Brasil. Belo Horizonte: Autêntica, 2003, p. 77 97.

GUIMARÃES, A. A. e VILLELA, B.C.F. O Professor-coordenador e as atividades de início de ano. In: GUIMARÃES, A. A et al. (Org.) O Coordenador Pedagógico e a Formação Docente. 13 edição, São Paulo: Edições Loyol, 2015.

GRINSPUN, M. P. S. Z. A Orientação Educacional: conflito de paradigmas e alternativas para a escola. São Paulo: Cortez, 2002.

LIMA, G.P. E SANTOS, M.S. O Coordenador Pedagógico na Educação Básica: desafios e perspectivas, Educare et Educare: Revista de Educação, Cascavel-PR, v.2,n.4,p.7790,jul/dez,2007.

MARCELO, G. Pesquisa sobre formação de professores: o conhecimento sobre aprender a ensinar. Revista Brasileira de Educação, n. 09. São Paulo: Anped, 1998.

PARO, V. H. Gestão democrática: participação na comunidade. São Paulo: Cortez, 1988.

PLACCO, Vera Maria Nigro de Souza. ALMEIDA, Laurinda Ramalho de; SOUZA, Vera Lucia Trevisan de (Coord.). O Coordenador Pedagógico e a formação de professores: intenções, tensões e contradições. Fundação Carlos Chagas. Estudos \& pesquisas Educacionais. São Paulo, Abril, 2011.

Revista de Administração Educacional, Recife, V. 1. Nº 2 - jul/dez. 2017 p. 49-70 
RECIFE, Escola Estadual de Referência em Ensino Médio. Projeto Político-pedagógico da Escola Estadual de Referência em Ensino Médio. 2016 (texto em formato digital)

Escola Estadual de Referência em Ensino Médio. Plano de Ação da Escola Estadual de Referência em Ensino Médio. 2016 (texto em formato digital)

Escola Estadual de Referência em Ensino Médio. Regimento Substituto da Escola Estadual de Referência em Ensino Médio. 2016 (texto em formato digital)

Revista de Administração Educacional, Recife, V. 1. No 2 - jul/dez. 2017 p. 49-70 